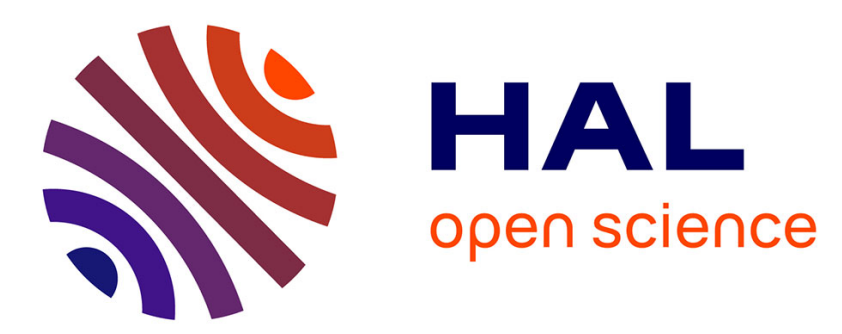

\title{
Elastic Modulus and Mechanical Loss Associated with Phase Transitions and Domain Walls Motions in PZT Based Ceramics
}

\author{
E. Bourim, Hassane Idrissi, B. Cheng, M. Gabbay, Gilbert Fantozzi
}

\section{- To cite this version:}

E. Bourim, Hassane Idrissi, B. Cheng, M. Gabbay, Gilbert Fantozzi. Elastic Modulus and Mechanical Loss Associated with Phase Transitions and Domain Walls Motions in PZT Based Ceramics. Journal de Physique IV Proceedings, 1996, 06 (C8), pp.C8-633-C8-636. 10.1051/jp4:19968136 jpa-00254568

\author{
HAL Id: jpa-00254568 \\ https://hal.science/jpa-00254568
}

Submitted on 1 Jan 1996

HAL is a multi-disciplinary open access archive for the deposit and dissemination of scientific research documents, whether they are published or not. The documents may come from teaching and research institutions in France or abroad, or from public or private research centers.
L'archive ouverte pluridisciplinaire HAL, est destinée au dépôt et à la diffusion de documents scientifiques de niveau recherche, publiés ou non, émanant des établissements d'enseignement et de recherche français ou étrangers, des laboratoires publics ou privés. 


\title{
Elastic Modulus and Mechanical Loss Associated with Phase Transitions and Domain Walls Motions in PZT Based Ceramics
}

\author{
E.M. Bourim, H. Idrissi, B.L. Cheng*, M. Gabbay and G. Fantozzi \\ GEMPPM, UMR 5510 du CNRS, Bât. 502, INSA Lyon, 69621 Villeurbanne cedex, France \\ * Department of Physics, South China University of Technology, Guangzhou 510641, China
}

\begin{abstract}
Elastic modulus (shear modulus $\mathrm{G}$ or Young's modulus E) and internal friction $\mathrm{Q}^{-1}$ were measured as a

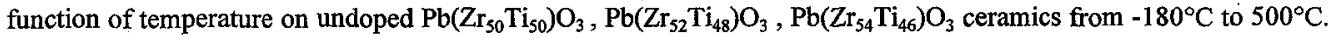
Experiments were performed at low and medium frequencies $(0.1 \mathrm{~Hz}-4 \mathrm{kHz})$. The $\mathrm{E}(\mathrm{T})$ curves show two anomalies which are due to following phase transitions: tetragonal to cubic $\left(T_{C}\right)$ and rhombohedral to tetragonal $\left(T_{R-T}\right)$. The $T_{C}$ temperatures are in good agreement with phase diagram from litterature. The $T_{\mathrm{R}-\mathrm{T}}$ temperatures allow to complete the phase diagram of the morphotropic phase boundary of PZT in the low temperature range. Moreover, $Q^{-1}(T)$ curves recorded at low frequencies show two relaxation peaks; their activation energy and relaxation time are determined using the Arrhenius plots. These two relaxation peaks could be attributed to the interaction of domain walls with point defects.
\end{abstract}

\section{INTRODUCTION}

Lead titanate zirconate $\mathrm{Pb}\left(\mathrm{Zr}_{\mathbf{x}} \mathrm{Ti}_{1-\mathrm{x}}\right) \mathrm{O}_{3}$ ceramics are one of the most common piezoelectric materials in industry: they are used as transducers between electrical and mechanical energy, such as phonograph pickups, air transducers, underwater sound and ultrasonic generators, delay-line transducers, wave filters etc. [1] Generally, all those applications need high piezoelectric constants as well as low electrical and mechanical losses. Variations of internal friction and elastic modulus as a function of temperature and excitation frequency can provide direct information on energy dissipation in the material. For example, Postnikov et al. [2] have shown that the internal friction in the PZT is not only associated with domain walls but also with point defects. The $\mathrm{Zr} / \mathrm{Ti}$ ratio in $\mathrm{Pb}(\mathrm{Zr}, \mathrm{Ti}) \mathrm{O}_{3}$, the nature and concentration of substituting elements, the shaping procedure of green bulk, the sintering temperature and atmosphere are the controlling factors which provide the suitable properties for applications. With their many applications and controlling factors, the PZT materials have been the subject of continuous research for the past few decades. In the present study, the elastic modulus and the internal friction were measured at different temperatures, in order to determine phase transition temperatures and to study the motion of domain walls.

\section{Samples and Experimental Procedures}

Undoped PZT ceramics were prepared by solid diffusion of $\mathrm{PbO}, \mathrm{ZrO}_{2}$, and $\mathrm{TiO}_{2}$ powders with the following $\mathrm{Zr} / \mathrm{Ti}$ ratio: $\mathrm{Pb}\left(\mathrm{Zr}_{0.50} \mathrm{Ti}_{0.50}\right) \mathrm{O}_{3}, \mathrm{~Pb}\left(\mathrm{Zr}_{0.52} \mathrm{Ti}_{0.48}\right) \mathrm{O}_{3}$ and $\mathrm{Pb}\left(\mathrm{Zr}_{0.54} \mathrm{Ti}_{0.46}\right) \mathrm{O}_{3}$. shortly called PZT50/50, PZT52/48 and PZT54/46.

Young's modulus $\mathrm{E}$ and internal friction $\mathrm{Q}^{-1}$ have been measured as a function of temperature. Samples were driven in flexural vibration at resonance frequency of about $3 \mathrm{kHz}$. Specimen dimensions, experimental measurement device and calculation formula were described in [3]. The measurements at low frequencies of shear modulus $G$ and internal friction $Q^{-1}$ were measured by an inverted pendulum. The temperature range is located between $-180^{\circ} \mathrm{C}$ and $500^{\circ} \mathrm{C}$. 


\section{RESULTS AND DISCUSSIONS}

The Figure 1 presents $E(T)$ and $Q^{-1}(T)$ curves obtained with PZT52/48 ceramic. The $E(T)$ curve shows two anomalies called $A_{1}$ and $A_{2}$ located at $375^{\circ} \mathrm{C}$ and $-69^{\circ} \mathrm{C}$. The $A_{1}$ anomaly of elastic modulus is correlated to a sharp internal friction peak called $P_{1}$. Both $A_{1}$ anomaly and $P_{1}$ peak are due to the phase transition from cubic to tetragonal phases. The $A_{2}$ anomaly is due to the second phase transition between tetragonal and rhombohedral phases. This $A_{2}$ anomaly is not correlated to an internal friction peak. Similar $E(T)$ and $Q^{-1}(T)$ curves were obtained for other composition PZT50/50 and PZT54/46 ceramics.

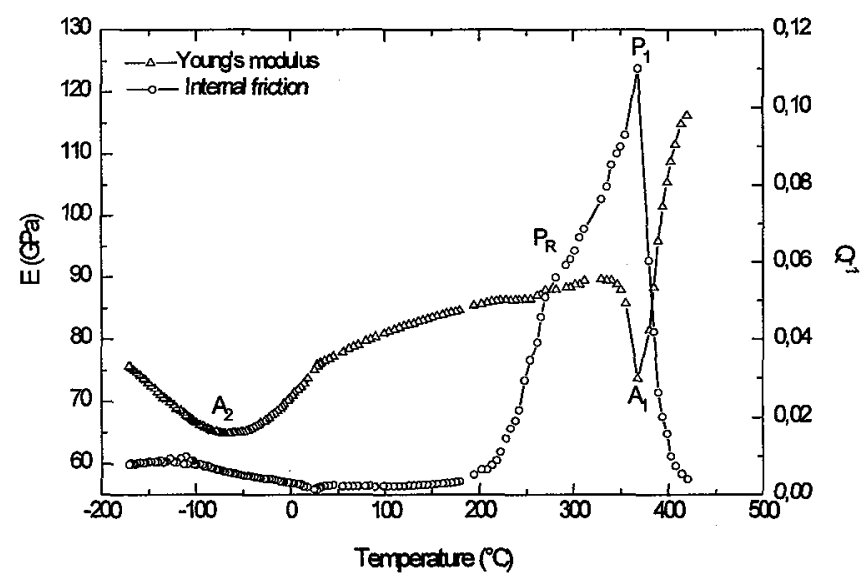

Figure 1: $E(T)$ and $Q^{-1}(T)$ at $k H z$ frequency.

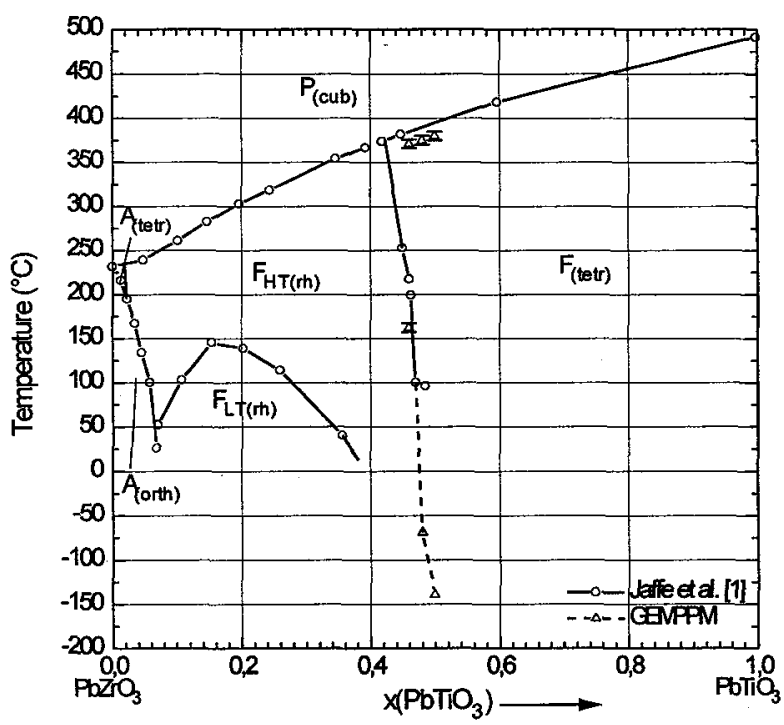

Figure 2 : Phase diagram of PZT. 
The Figure 2 shows the phase diagram from Jaffe et al. [1] on which our results on phase transition temperatures $T_{C}$ and $T_{R-T}$ have been added. About $T_{C}$ our results are in good agreement with Jaffe's diagram. Moreover, about the $\mathrm{T}_{\mathrm{R}-\mathrm{T}}$ temperatures, our results allow to complete the morphotropic region of the phase diagram located below $0^{\circ} \mathrm{C}$.

About the $Q^{-1}(T)$ curve shown in Figure 1, it is possible to divide the temperature range according to the level of internal friction. From the low temperature $-180^{\circ} \mathrm{C}$ to $0^{\circ} \mathrm{C}, \mathrm{Q}^{-1}$ decreases monotonically to a low level. Between $0^{\circ} \mathrm{C}$ and $180^{\circ} \mathrm{C}, \mathrm{Q}^{-1}$ remains constant. Above $180^{\circ} \mathrm{C}, \mathrm{Q}^{-1}$ increases strongly up to a maximum of the $P_{1}$ peak ( at the Curie temperature ). In the paraelectric region, the drastic decreasing of $Q^{-1}$ remember us that the mechanisms of energy dissipation in ferroelectric state are obviously linked to the motion of domain walls. The same shape of the $E(T)$ and $Q^{-1}(T)$ curves are obtained for all three compositions of PZT ceramics.

In order to determine which anelastic event is located at $P_{R}$ in the increasing part of the $Q^{-1}(T)$ curves at kilohertz, the measurements of $\mathrm{G}$ and $\mathrm{Q}^{-1}$ versus temperature were performed at low frequencies of 0.1 to $1 \mathrm{~Hz}$ on two pendulums (which allow to cover the total temperature range). The results obtained with the PZT 52/48 ceramic are shown on Figures 3 (low temperature) and 4 (high temperature). The G(T) curves show the $A_{1}$ and $A_{2}$ anomalies of shear modulus due to two phase transitions: $T_{c}$ and $T_{R-T}$.

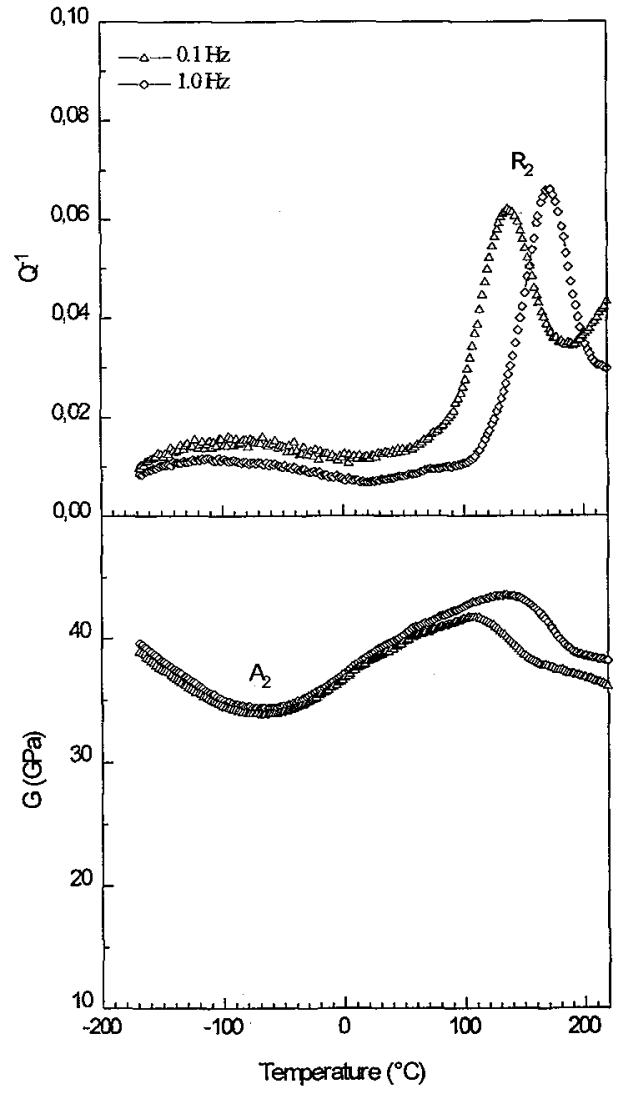

Figure $3: Q^{-1}(T)$ and $G(T)$ at low temperature.

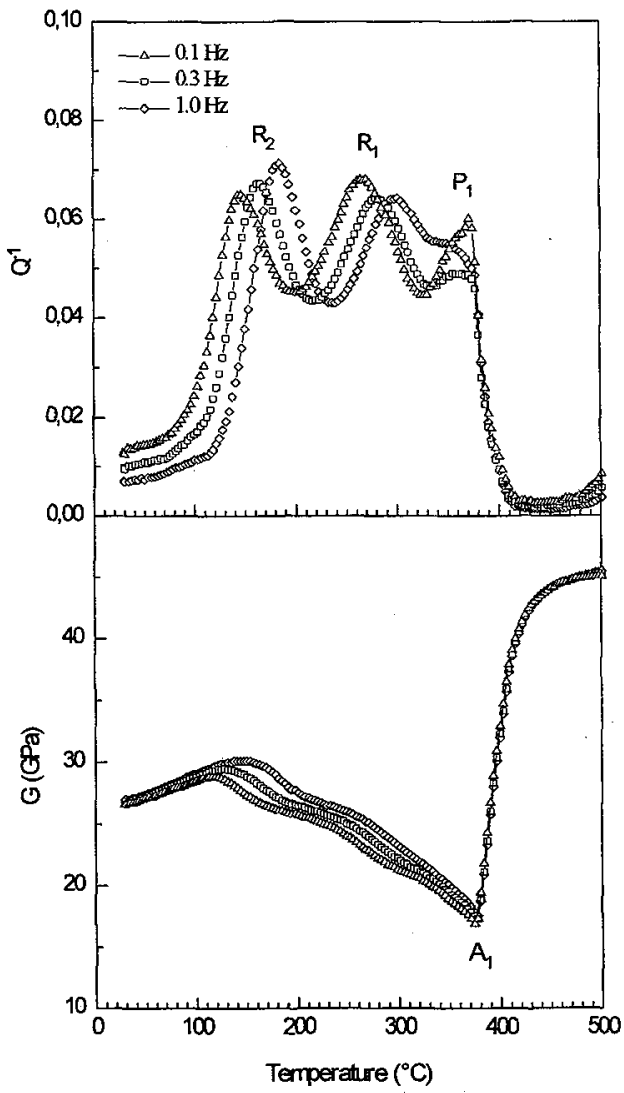

Figure $4: Q^{-1}(T)$ and $G(T)$ at high temperature. 


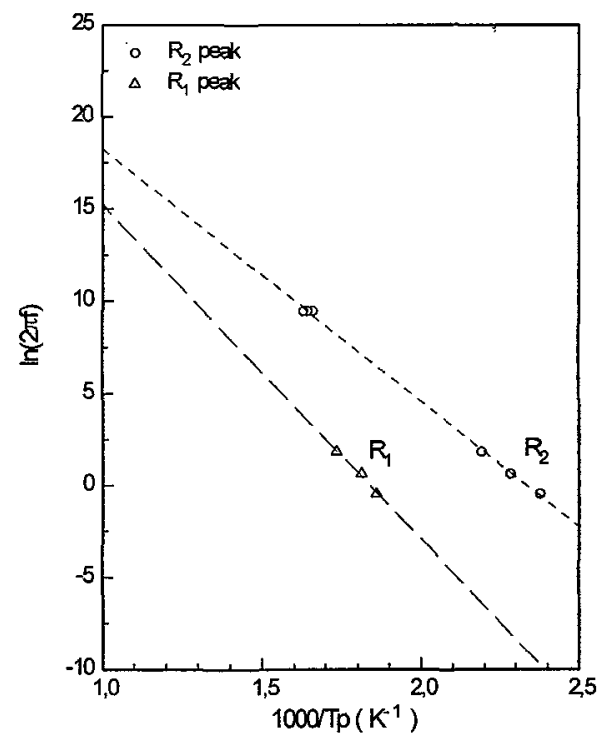

Figure 5: Arrhenius plot for PZT52/48.
On the $Q^{-1}(T)$ curves, two internal friction peaks $R_{1}$ and $R_{2}$ are observed. These two peaks have a relaxation behavior because they are frequency dependent.

The Arrhenius plot corresponding to this two peaks are given in the Figure 5. It is of interest to note that the $R_{2}$ peak is connected to the shoulder observed on $Q^{-1}(T)$ at kilohertz frequency.

Table 1: Activation parameters of $R_{1}$ and $R_{2}$ peak in the three PZT ceramics.

\begin{tabular}{|c|c|c|c|}
\hline Peak & PZT50/50 & PZT52/48 & PZT54/46 \\
\hline $\mathrm{R}_{1}$ & $\mathrm{H}=1.63 \mathrm{eV}$ & $\mathrm{H}=1.56 \mathrm{eV}$ & $\mathrm{H}=1.63 \mathrm{eV}$ \\
& $\tau_{0}=8 \times 10^{-16} \mathrm{~s}$ & $\tau_{0}=3 \times 10^{-15} \mathrm{~s}$ & $\tau_{0}=1 \times 10^{-15} \mathrm{~s}$ \\
\hline $\mathrm{R}_{2}$ & $\mathrm{H}=0.99 \mathrm{eV}$ & $\mathrm{H}=1.17 \mathrm{eV}$ & $\mathrm{H}=0.93 \mathrm{eV}$ \\
& $\tau_{0}=1 \times 10^{-12} \mathrm{~s}$ & $\tau_{0}=1 \times 10^{-14} \mathrm{~s}$ & $\tau_{0}=2 \times 10^{-12} \mathrm{~s}$ \\
\hline
\end{tabular}

The Table 1 gives the activation energy and the relaxation time for the $R_{1}$ and $R_{2}$ peaks. Fot the $R_{2}$ peak, the magnitude of the relaxation time is coherent with a point defect relaxation and the $R_{2}$ relaxation peak could be due to the interaction between domain walls and oxygen vacancies because the activation energy for diffusion of oxygen vacancy is about $0.9 \mathrm{eV}$. In order to verify this hypothesis, we intend to modify the concentration of oxygen vacancy by annealing in vaccum.

Concerning the $R_{1}$ peak, its activation energy is high (about $1.6 \mathrm{eV}$ ) and we intend to study the influence of annealing and strain amplitude. One can notice that the $R_{1}$ peak is not observed in the kilohertz range because its temperature is higher than the Curie temperature.

\section{Conclusion}

The $\mathrm{E}(\mathrm{T})$ curves lead to the determination of new points in the phase diagram of PZT in the morphotropic region. $Q^{-1}(T)$ curves obtained at low frequencies show two relaxation peaks $R_{1}$ and $R_{2}$. The $R_{2}$ peak located at lower temperature, could be attributed to the interaction of domain walls and oxygen vacancies. The $R_{1}$ peak is probably due to the interaction of domain walls and another point defect.

\section{Reference}

[1] Jaffe, B., .Cook, W.R.Jr., and Jaffe, H., 'Piezoelectric Ceramics', Academic Press, London and New York (1971) p.271

[2] Postnikov, P.V., Pavlov, V.S., Gridev, S.A., and Turkov, S.K., Soviet Phys. -Solid State, 10 (1968) 1267.

[3] Cheng, B.L., Gabbay, M., Duffy, W. Jr., and Fantozzi, G., J. Alloys and Compounds, 211/212, (1994) 344-347 